\title{
An Improved Form of Book-Shelving for Branch Lending Libraries. ${ }^{1}$
}

\begin{abstract}
A $\mathrm{T}$ the Aberdeen meeting of the Library Association, Mr. A Thomas Mason read an interesting paper (see Library, vol. vi., p. 263) on a new method of arranging a lending library, and the paper, when read, suggested to me that a somewhat similar arrangement I bad a little while previously designed for adoption in the new branch libraries, then in course of formation in Birkenhead, might usefully be described to my fellow members. Since then several practical librarians have witnessed the working of this arrangement, and, as I understand it has been introduced in one or more other libraries, a description of the plan may prove of more than momentary interest.
\end{abstract}

It would be better to first explain the plan as clearly as can be done in a paper; and then give more appreciable ideas of experience gained in the actual working.

For a description of the book-casing or shelving itself, I may say in the first place, it is planned to form the barrier between the public and the library officials, in place of the usual counters, railing, \&c. The shelving is in single stacks (i.c., books on one side only), shelves $7 \frac{1}{2}$ or 8 inches in depth, open on both sides, but the front open to the public covered with an open wire-mesh work of $\mathrm{If}$ inch mesh. If brass is used for this, instead of iron wire, a neat and smart appearance results.

The book-casing stands 7 feet 6 inches high, and the shelves as far as possible or convenient are 2 feet 9 inches, or 3 feet in length. From the public side, which we may term the front, the first two feet upwards from the floor is blocked or boxed with skirting and panelling, and this portion is open on the librarian's side for two shelves, to accommodate long sets of magazines, volumes of music, and other tall or awkward sizes of books.

\footnotetext{
' Contribated to the Eighteenth Annual Meeting of the Library Ass seiation, Cardif, September, 1895, and read at a Monchly Meeting, Londun, feiurury, 1896.
} 
At the distance of two feet from the floor, the open wire-work protected shelves commence. A space of 4 feet 6 inches is then given, calculated to accommodate six rows of shelves and on the top of this, one more shelf is provided, which like the two bottom shelves is concealed on the public side, but open on the inner side; and is utilised for books awaiting repairs, binding or enquiries, sets of magazines, or other books it may not be desirable to display to the gaze of the public-the blocked front to the public being neatly panelled for utilisation as notice-boards, or for name-plates to indicate the precise class of books which may be shelved beneath.

The casing is thus 7 feet 6 inches high, with six shelves in each standard, open to the view of the public, but protected by the wire-mesh described. The boxing of the top and two lower shelves is to lessen inconvenience to the public in consulting books on shelves too high or too low for easy search, and yet retaining the space for book-storage; and the wisdom of placing the lowest open shelf at two feet from the floor, has been proved by the convenient and comfortable manner in which the public have so far used the shelving.

The books are arranged with the fore-edge to the librarian's side, and the backs with their lettered titles facing the public. The difficulty of the assistants finding the books readily on the library service side is obviated by a free use of shelf-tags, and numbering books on the fore-edge with rubber or metal figure tooling.

The public, in selecting their books, are expected to push the book back from the wire-work, so that the librarian receives some assistance in finding the work selected, and is enabled to notice quickly the book required, by its projection from its neighbours. To prevent the book being projected over the edge of the shelf, with a consequent fall to the floor, each shelf on the library service side is provided with an upward projecting lip, thus preventing the books being pushed clear from the shelf. Practical use proves this lip need not exceed a projection of one-eighth of an inch-in fact, more is a disadvantage. The wire-work guard may be constructed in the form of hinged and locked doors, or as shutters with simple fastenings to prevent the public tampering with them. This is necessary to allow the library assistants free access to the front of the books, for arranging, dusting, checking, labelling, during the hours the library is closed to the public. 
The general arrangement of the book-cases may be said to be that which permits the most economical display of the greatest number of books. The shape or direction of the cases does not affect the general principle of the plan, so long as the public is allotted sufficient space for conveniently inspecting the titles of the books. If a wall be opposite a book-case, then three feet may be found the minimum space to allow between the two, becanse though the library staff may work in less space, the public could not easily do so, and if book-case faced book-case, with tho public asing the space between, I should be loath to give less than four feet six inches clear between the two.

There is scarcely any necessity to speak of the systems of charging to be adopted with the plan, as any of the systems in use may be used, according to preference, though the indicatorsystem is least adaptable.

The advantages I anticipated from the adoption of this system were several, but two stood out prominently. In the first place, the system is an advanced form of indicator, where the books themselves take the place of numbered blocks; and, secondly, it is a concession, under safe-guarded limits, of the admission of the public to the shelves. After all, the best catalogue is a poor guide to the aimless reader, who goes so fre fuently to swell the ranks of the too omnivorous novel readers, and librarians are justified in almost any experiment which has for its aim the lowering of the heavy percentage of fiction issued from our public lending libraries, or of making the public better acquainted with other and higher branches of literature. The public at our libraries are not compelled to seloct their books from these shelves, the looking out of books is optional, but the temptation is great, to choose from a sight of the backs of the books a work more suited to their individual tastes, than is likely to be found by poring over a catalogue previous to visiting the library.

It is in this direction I have large hopes that it may lead to a considerable decrease in the issues of fiction. I have not placed novels or juvenile books in these cases up to the present. Possibly, if I had done so, their location would have most frequently been indicated. by an array of empty shelves, and the principal object I had in view-that of making the people better acquainted with those books in the libraries not embraced in the classification, "pruse fiction"-prould have been frustrated.

I believed the bringing of the books to the near sight of the 
public would bring about an improved knowledge of higher literature, and induce a better selection of reading. I am glad to say the result so far has justified the experiment ; for, in Birkenhead, where the branch libraries are so shelved, the issues of prose fiction are found to be ten per cent. below the issues of the same class at the central library, where the old system prevails, and, moreover, there is a pleasing high percentage in the more solid classes of reading.

Birkenhead Public Library.

W. MaY.

\section{DISCUSSION.}

Mr. JOSEPH GilbuRT: The public is very little wiser for seeing the backs of books. Misleading and non-leading character of titles has been the subject of frequent comment. The catalogue, fully indexed and cross-referenced, is our best means wherewith to show the public what books contain.

Mr. FoSKeTT : Mr. May's paper gives a lucid explanation of the writer's experiment, but, like some other departures, it seems to have been called into existence by adverse criticism in relation to the issue of fiction. I rather deprecate changes from orderly and customary methods for any such reasons, as in most cases they are founded on a misconception of statistics. Mr. May does not happen to belong to that type of librarian who is constantly altering his methods, and it is, therefore, the more to be regretted that he is not present to reply to the objections which have been raised. There secms to be a consensus of opinion against him, and I cannot see valid grounds for encouraging such a departure. Library assistants do much work at the shelves during the quiet times of the day ; but even the simple operation of dusting would interfere with the cage arrangement, as it appears to be a sine qua non that the backs of the books should face the borrowers. I cannot believe that the abbreviated and often strangely misleading outside titles are likely to turn any inveterate novel reader from the error of his way. Evolution in reading is a gradual process which can only be assisted by a good catalogue and also by talks and lectures to readers. I think our most cordial thanks are due to Mr. May for bis candid statement of what is probably only a tentative arrangement.

Mr. R W. MouLD : Some six or seven years ago a plan practically identical with that now subnitted by Mr. May was devised by the chief librarian of the Birmingham Public Libraries, Mr. Mullins, who had in view the provision of an unmistakable indicator of the books in the library. It has not, however, been used at Birmingham so far. The arrangement would be somewhat difficult to work in very large liliraries, but seems to be specially advantageous for small branches. The difficulty 23 to the inadequacy of the publisher's titles on the backs of the books could be overcome by supplementary lettering under the librarian's direction. 
Mr. W. A. TAYLOR : I think that one of the chief factors bearing on the real success of any system of open or semi-open access is the amount of floor space available for the shelving and for the public. It is possible to store books anywhere, but with an extensive collection it is not always possible to exhibit the whole of the books to the public.

Mr. ROBERTS : 1 should like to mention that at Newcastle all new books are placed in special cases in the lending or reference libraries with a notice that they are new books, and, in the case of those belonging to the lending library, the day on which they will be put into circulation is stated. This system enables diligent readers to keep their catalogues up to date. The cases are placed in full view of the readers, but they are not allowed to handle the books. The system is found to work very well.

Mr. Macalister : Our thanks are due to Mr. May, and I cordially thank him, for laying before us so completely and clearly a plan for popularising the lending library, which he has worked out with such conscientious elaboration. But he has not convinced me that it should be copied. The title of a book, and particularly the binder's title, is usually a very poor guide to its contents, and unless he is prepared to allow his readers to examine a book the title of which has tempted them, before they decide to take it, I fail to see what advantage reading the titles on the backs of the books has over reading the probably fuller titles in a catalogue. In my opinion, there is no middle way between a good catalogue and "open access." I use no library in which I cannot examine the books, and what I require for myself, I would, whenever the conditions of the library permit it, grant to the public.

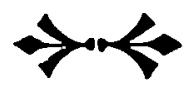

